University for Business and Technology in Kosovo

UBT Knowledge Center

UBT International Conference

2018 UBT International Conference

Oct 27th, $10: 45$ AM - 12:15 PM

\title{
Impact of temperature on beer fermentation kinetics
}

\author{
Hasime Manaj \\ University of Tirana \\ Luljeta Pinguli \\ University of Tirana \\ Ilirjan Malollari \\ University of Tirana \\ Anisa Dhroso \\ University of Tirana, anisa.dhroso@fshn.edu.al
}

Follow this and additional works at: https://knowledgecenter.ubt-uni.net/conference

Part of the Food Science Commons

\section{Recommended Citation}

Manaj, Hasime; Pinguli, Luljeta; Malollari, Ilirjan; and Dhroso, Anisa, "Impact of temperature on beer fermentation kinetics" (2018). UBT International Conference. 172.

https://knowledgecenter.ubt-uni.net/conference/2018/all-events/172

This Event is brought to you for free and open access by the Publication and Journals at UBT Knowledge Center. It has been accepted for inclusion in UBT International Conference by an authorized administrator of UBT Knowledge Center. For more information, please contact knowledge.center@ubt-uni.net. 


\title{
Impact of temperature on beer fermentation kinetics
}

\author{
Hasime Manaj ${ }^{1}$, Luljeta Pinguli ${ }^{1}$, Ilirjan Malollari ${ }^{1}$, Anisa Dhroso ${ }^{1}$ \\ ${ }^{1}$ Department of Industrial Chemistry, Faculty of Natural Sciences University of Tirana \\ hasime.manaj@fshn.edu.al
}

\begin{abstract}
Microbial processes are highly dependent on temperature. This paper aims to study the influence of temperature on fermentation process on experimental and industrial scale. We were focused to determine the preexponential coefficients and the activation energy for experimental and industrial conditions and to quantify the amount of heat to be removed from fermenter to keep it under constant temperature during fermentation process. Substrate used for fermentation was beer industrial wort $12^{0}$ Balling and yeast strain used was bottom fermentation yeast "Saccharomyces Carlsbegensis SP 35". Evaluation and comparison of kinetic parameters in different fermentation conditions were carried out. Temperatures used for different batches in industrial trials were 5, 20, 25 and $35^{\circ} \mathrm{C}$ and 8,12 and 16 ${ }^{\circ} \mathrm{C}$ for experimental trials. Kinetic models developed were able to predict with a relatively high accuracy the experimental results achieved under non-thermal conditions and can be used to simulate the industrial process of beer production.
\end{abstract}

Keywords: Kinetic Model, Fermentation, Activation Energy, Coefficients.

\section{Introduction}

It is common in industrial beer fermentations to operate at an experimentally determined optimal growth temperature for the yeast being used. Depending on how the fermentation progresses, the temperature can be raised (i.e., to speed up a slow fermentation) or lowered (i.e., to offset the formation of undesirable flavor and aroma compounds) to keep the fermentation on schedule and to maintain the desired product quality. Ideally the temperature should not have to be varied in this way, but unforeseen circumstances often arise that require temperature variation. In this article a simplistic model of beer fermentation is used to perform an optimal temperature control study of beer fermentation [2]..

The fermentator cooling temperature was the single available parameter to control. Many authors has noted that the kinetic rate constants in biological reactions of yeast follow an Arrhenius-type temperature dependence up to a defined optimal growth temperature. Most researchers, as a first approximation, have assumed a temperature dependence only on the maximum specific rate parameters and have ignored any similar effects on other kinetic parameters. The objective of this study was to predict a kinetic model based on experimental and industrial scale trials on temperature impact directly on fermentation dynamics. Optimal control theory was applied to the process 
of batch beer fermentation [3]. The performance was evaluated based on substrate consumption kinetics. Kinetic parameters were calculated based on well-known Arrhenius model.

In fitting the model to data it was found that these parameters did vary with temperature and that they followed an Arrhenius dependency quite closely.

\section{Material and method}

Experimental and industrial fermentation were carried out almost in the same condition. As substrate was used $12^{0}$ Balling beer wort, inoculated with Saccharomyces carlsbegensis SW35 bottom yeast in cell density $8 \%$. Industrial trials were carried out at "Stefani \& Co " brewery in Tirana, Albania. Glucose measurements were performed at certain time intervals and fermentation progression was performed until fermentation ended at a constant value of the residual extract [8]. Periodic fermentation was carried out in small bioreactors with a volume of 11 . Fermentation temperatures $5,20,25$ and $35^{\circ} \mathrm{C}$ were used in experimental conditions and temperatures 8,12 and $16{ }^{\circ} \mathrm{C}$ under industrial conditions. We tried to provide similar experimental fermentation conditions as in industry, by inoculating the same yeast quality with the same vitality and cell density. The performance of substrate consumption in relation to time was monitored.

Kinetic parameters: The metabolic activity of enzymes increases with increasing temperature as long as the temperature does not get too high. The dependency observed is of Arrhenius type. In order to have a better understanding of the fermentation process performance, kinetic parameters should be considered, such as the specific velocity of substrate consumption, $\mu$ and so on [11]. Determination of this velocity is carried out through simple linearization of Arrhenius equation, since this law applies only to low temperatures, which correspond to our fermentation conditions. Applied Arrhenius law, regarding both experimental development environments, can be written as [1]:

$$
\begin{gathered}
\mu_{1}=A_{1} \exp \left(-\frac{E_{a_{1}}}{R T}\right) . \\
\mu_{2}=A_{2} \exp \left(-\frac{E_{a_{2}}}{R T}\right) .
\end{gathered}
$$

where, the index "1" stands for laboratory conditions while the index "2" stands for industrial conditions. Determination of kinetic parameters is donne through linearization form of Arrhenius equation [5]:

$$
\ln \left(\mu_{i}\right)=\ln \left(A_{i}\right)-\frac{E_{a_{1}}}{R} \cdot \frac{1}{T}
$$

Where, the index $i=1,2$ while the values of $\mathrm{T}$ vary from the fermentation conditions in each environment. Further, the linearization continues as: 


$$
\mathrm{y}_{i}=\mathrm{b}_{i}-\mathrm{a}_{i} \mathrm{x} .
$$

Where: $\quad y_{i}=\ln \left(\mu_{i}\right), b_{i}=\ln \left(A_{i}\right), a_{i}=-E_{a i} / R$ and $x=1 / T$

Also, it should be noted that the specific growth rate is given as [9], [10]:

$$
\mu_{i}=\frac{\Delta s_{i}}{\Delta t} .
$$

Where: $\Delta s_{i}=s_{0}-s_{p}$ and $\Delta t=t_{p}-t_{0}$

In order to determine constants $\underline{b}_{\underline{i}}$ and $\underline{a}_{\underline{i}}$ values we used Microsoft Office Excel.

\section{Results and discussion}

We evaluated the performance of laboratory conditions (fig. 1) for substrate concentration with time, for yeast in different fermentation conditions. In order to have a better understanding we evaluated these parameters in industrial conditions, which are depicted in figure 2 .

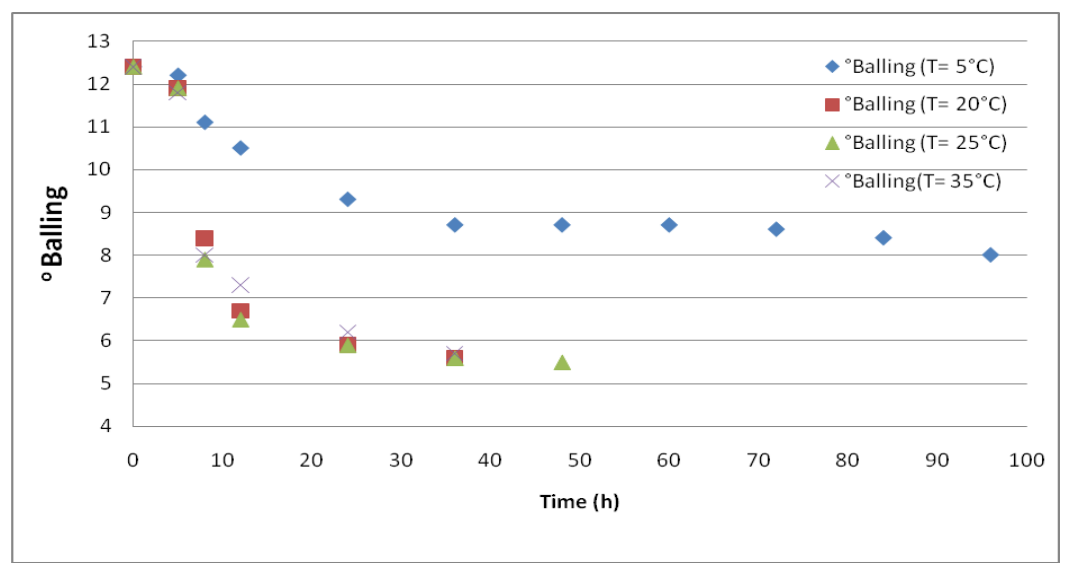

Fig. 1. Dependence of substrate concentration in ${ }^{\circ}$ Balling at hour time for yeast under different fermentation conditions, under laboratory conditions.

As we can observe, for all four cases the fermentation extract is almost at $5.6 \%$ of the concentration of sugar consumption, depending on time duration. On the other hand, it is noticed that the fermentation process time varies from the fermentation conditions and this is clearly apparent from the graphic representations for each case, where in the case of fermentation at a low temperature of $5^{\circ} \mathrm{C}$ the fermentation process requires a relatively short time frame more than 2 weeks since the yeast under these conditions fails to develop its full potential function, while in the other 3 cases corresponding to the temperatures of 20,25 and $35^{\circ} \mathrm{C}$, the yeast reaches consume a shorter time of glucose for approximately 3-4 days, producing a greater amount of alcohol. 


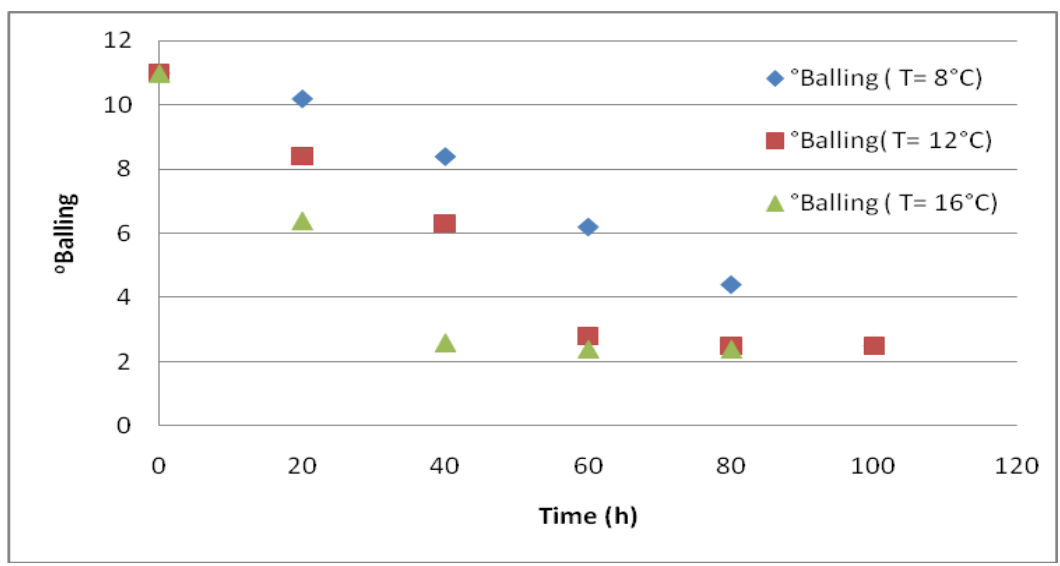

Fig. 2. Dependence of substrate concentration in ${ }^{\circ}$ Balling at hour time per yeast under different fermentation conditions under industrial conditions

Kinetic parameters: To determine the values of $\underline{b}_{i}$ and $a_{i}$ constants we use Microsoft Office Excel package and follow the steps below:

The following table is created for each of the premises and the $y_{i}$ and $x_{i}$ values are determined, namely the following:
a) Laboratory conditions, (1) ;
b) Industrial Conditions, (2)

Table 1. Summary table of the values of $\mathrm{y}_{1}$ and $\mathrm{x}_{1}$ for the process of fermentation under laboratory conditions.

\begin{tabular}{cccc}
\hline$T_{1}\left({ }^{\circ} \mathrm{C}\right)$ & $\mu_{1}$ & $1 / T_{1}$ & $\ln \left(\mu_{1}\right)$ \\
\hline 5 & 0.0333 & 0.2 & -3.4012 \\
20 & 0.18889 & 0.05 & -1.6666 \\
25 & 0.14375 & 0.04 & -1.9397 \\
35 & 0.18611 & 0.02857 & -1.6814 \\
\hline
\end{tabular}

Table 2. Summary table of the values of $\mathrm{y}_{2}$ and $\mathrm{x}_{2}$ for the process of fermentation under industrial conditions.

\begin{tabular}{cccc}
\hline$T_{2}\left({ }^{\circ} \mathrm{C}\right)$ & $\mu_{2}$ & $1 / T_{2}$ & $\ln \left(\mu_{2}\right)$ \\
\hline 8 & 0.085 & 0.125 & -2.4651 \\
12 & 0.10625 & 0.08333 & -2.242 \\
16 & 0.14333 & 0.0625 & -1.9486 \\
\hline
\end{tabular}

1)The dependence $y_{i}=f(x i)$ is evaluated and the linear characteristic equation is shown and the correlation coefficient for each case are determined. 


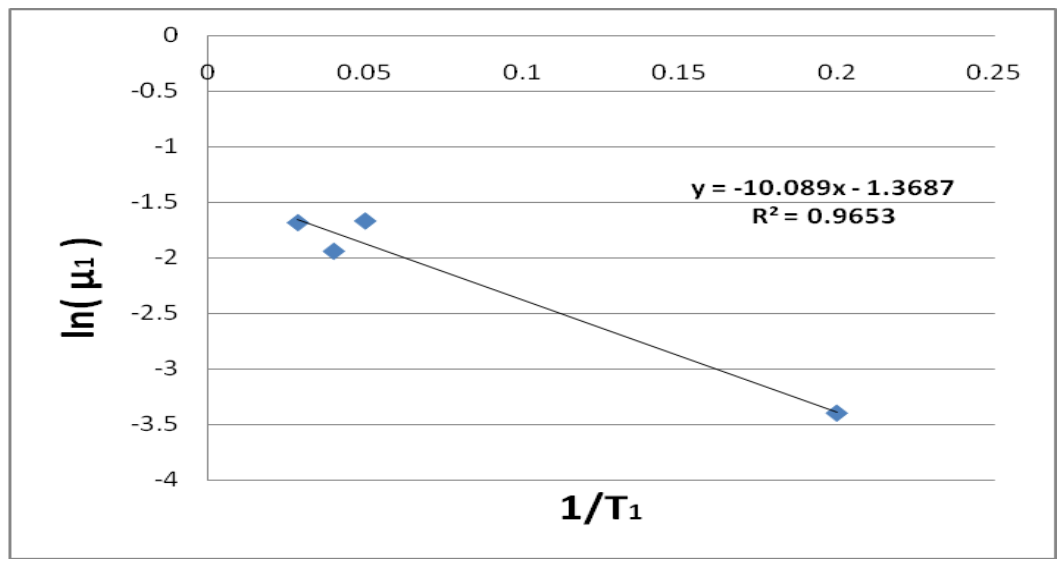

Fig. 3. Dependence of $y_{1}$ in $f\left(x_{1}\right)$ for the fermentation process under laboratory conditions

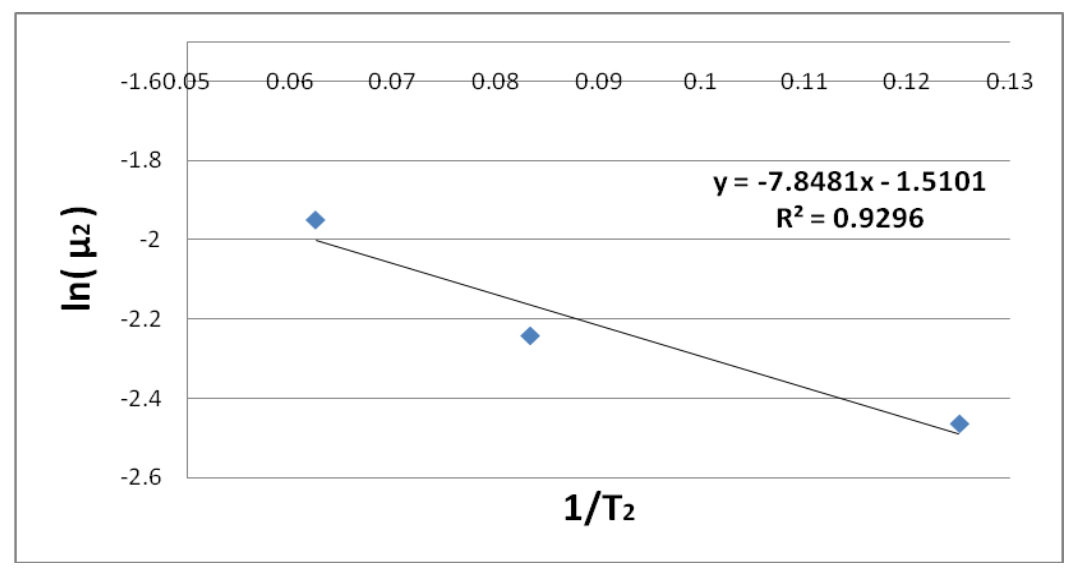

Fig. 4. Dependence of $y_{2}$ in $f\left(x_{2}\right)$ for the fermentation process under industrial conditions.

2)From the characteristic line equation, we determine the $b_{i}$ and $a_{i}$ coefficients and then, based on the respective formulas, we determine the equilibrium constants $\mathrm{E}_{\mathrm{ai}}$ and $\mathrm{A}_{\mathrm{i}}$, taking into account the constant value of the gases $\mathrm{R}=8.314 \mathrm{~J} / \mathrm{gmolK}$.

a) Laboratory conditions, (1):

$\mathrm{b}_{1}=-1,368$ and $\mathrm{a}_{1}=10.08$ from where: $\mathrm{A}_{1}=0.25462$ and $\mathrm{E}_{\mathrm{a} 1}=83.8051 \mathrm{~J} / \mathrm{gmolK}$.

b) Industrial conditions, (2):

$\mathrm{b}_{2}=-1,5$ and $\mathrm{a}_{2}=7.93$ from where: $\mathrm{A}_{2}=0.223130 .25462$ and $\mathrm{E}_{\mathrm{a} 2}=65.9383 \mathrm{~J} / \mathrm{gmolK}$

Production and removal of heat in ferments at industrial scale:

During the metabolism of the carbohydrate from yeast, a certain amount of energy is released which is used in the biosynthesis of cellular material or the production of 
other products or partly released as heat. This free energy is calculated from the general equation of glycolysis:

$$
\text { Glukozë }+2 \mathrm{Pi}+2 \mathrm{ADP} \rightarrow 2 \mathrm{Etanol}+2 \mathrm{CO}_{2}+2 \mathrm{ATP}
$$

Calculation of the free energy for each stage of this reaction will give a final value of $157 \mathrm{KJ} / \mathrm{mol}$ [ 7] . However, ATP is not included in the calculation produced by complementary cell reaction $(2 \mathrm{ATP} \rightarrow 2 \mathrm{ADP}+2 \mathrm{Pi})$ thus producing an amount of : $2 \times 31=62 \mathrm{KJ} / \mathrm{mol}$.

The total amount of heat can be calculated as $157+62=219 \mathrm{KJ} / \mathrm{Mol}$ fermented glucose (based on different assumptions we can obtain different values). Using the values calculated above, we can give the overall heat obtained by a typical fermentation process. If the liquor to be used for fermentation has an initial extract 120Plato means that the juice contains approximately $12.6 \mathrm{~kg}$ of the extract / heel of which $9.5 \mathrm{~kg}$ are fermentable. $219 \mathrm{KJ} / \mathrm{mol}$ glucose is equivalent to $1217 \mathrm{KJ} / \mathrm{kg}$ of glucose. So, since fermentation of $1000 \mathrm{hl}$ cider can be produced:

$$
1000 \times 9.5 \times 1217=11.5 \mathrm{GJ}
$$

This amount of heat is not uniformly obtained in fermentation, however, at the maximum fermentation speed this heat reaches the peak. This peak is about $0.22 \mathrm{~kg}$ extract / hl / hour. Thus, in fermentation of $1000 \mathrm{hl}$ the maximum heat of the coolant quantity is:

$$
1000 \times 0.22 \times 1217=0.26 \mathrm{GJ} / \mathrm{h}
$$

In order to realize the cooling of the beer, we must remove the heat produced which will depend on the temperature amplitude. Expression of this equation is:

$$
\mathrm{Q}=\mathrm{M} \times \mathrm{Cp} \times \Delta \mathrm{T}
$$

Where: $\mathrm{Q}-$ is the heat in $\mathrm{KJ}, \mathrm{M}$ - is the mass of beer in $\mathrm{kg}$,

$\mathrm{Cp}$-is the specific heat at $\mathrm{KJ} / \mathrm{kg}{ }^{\circ} \mathrm{C}, \Delta \mathrm{T}$ - is the difference in the beer temperature. For example: if a fermenter with $1000 \mathrm{hl}$ capacity and specific heat of $\mathrm{Cp}=4.05 \mathrm{KJ} / \mathrm{kg} \cdot \mathrm{C}$ will cool it from $15^{\circ} \mathrm{C}$ to $5^{\circ} \mathrm{C}$, the amount of heat to be removed will be:

$$
1000 \times 1000 \times(15-5) \times 4.05=4.05 \text { GJ }
$$

If the cooling speed reaches $1{ }^{\circ} \mathrm{C} / \mathrm{h}$ in the same way as above, we will also give the cooling speed:

$$
1000 \times 1000 \times 1 \times 4.05=405 \mathrm{MJ} / \mathrm{h}
$$

\section{Conclusion}

Microbial processes are processes that are highly dependent on temperature. The very fact that in some cases we use temperature as an inhibitory factor or an activator of microbial processes means a lot for us. Chemical engineering is of interest to both sides of the coin and the temperature of microorganism inhibition, which is used in the case of preservation of products or pasteurization and sterilization to model the processes and designed equipment to achieve this objective, but very important is the activation temperature to obtain the optimum speed of the microbial reaction. 
In the case of consideration, the temperature influence on the performance of the fermentation process has been taken into consideration in this subject. The yeast fermentation process with yeast essence is an exothermic process that releases considerable amounts of energy. Determination of temperature dependence coefficients is very important for modeling and designing bioreactors, particularly for designing the cooling and removal mode of heat released from the fermentation process. Experiments carried out on an experimental and industrial scale used approximate kinetic constants and an approximate calculation was made of how much energy should leave the bioreactor to keep the process at constant temperature.

\section{The values received are: -Kinetic constants:}

$\mathrm{A}_{1}=0.25462, \mathrm{E}_{\mathrm{a} 1}=83.8051 \mathrm{~J} / \mathrm{gmol} ; \mathrm{A}_{2}=0.22313, \mathrm{E}_{\mathrm{a} 2}=65.9383 \mathrm{~J} / \mathrm{gmol}$

-The amount of energy needed to be removed from the bioreactor to keep the process at constant temperature: $\mathrm{Q}=4.05 \mathrm{GJ}$.

In conclusion, this kinetic model with the values calculated for the temperature function for the important parameters was able to predict with a relatively high precision the experimental results achieved under non-thermal conditions. On the other hand, this model can be used to simulate the industrial process of beer production under different operating conditions and to detect errors during the development of the process at each step.

\section{References}

1. Agrawal, P., Lim, H.C.: Advances in Biochemical Engineering Biotechnology, Vol. 30, Fiechter, A. Ed: Springer-Verlag, New York (19841) 61

2. Douglas, A.G., Rarnirez, W.F.: Optimal temperature Control for Bach Beer Fermentation (1987)

3. Engasser,J.M., Marc,I., Moll,M., Duteurtre, B.: EBC Congress

4. Haas, W.R., Tavlarides, L.L., Wnek,W.J.: AIChE J 20(4), (1974) 707

5. IMSL Software Library, Nonlinear Regression Routine ZXSSQ.

6. Kirk,D.E.: Optimal Control Theory: An Introduction Prentice-Hall, Englewood Cliffs, NJ (1970) 228

7. Mahler, H,S., Cordes, E.H.: Biological chemistry, New York, Harper and Row, (1969)

8. Miedaner, H.: The Brewer, February (1978) 33

9. Parulekar, S.J., Lim, H.C.: in Advances in Biochemical Engineeringl Biotechnology, Vol. 32, Fiechter, A. Ed: Springer-Verlag, New York, (1985) 207

10. Wang, N.S., Stephanopoulos, G.: CRC: Crit. Rev. Biotechnol., 2( 1), (1985) 1

11. Williams, L.A., Am, J.: Enol. Viticult., 33(3), (1982) 149, (1981) 579. Eds. Academic, London, (1971) 91 